\title{
Influence of Intercalation Methods in Properties of Clay and Carbon Nanotube and High Density Polyethylene Nanocomposites
}

\author{
Bruna Louise Silva ${ }^{a}$, Fernanda Czerkies Nack ${ }^{a}$, Carlos Mauricio Lepienski, \\ Luiz Antonio Ferreira Coelho ${ }^{a}$, Daniela Becker ${ }^{a *}$ \\ ${ }^{a}$ Centro de Ciências Tecnológicas - CCT, Universidade do Estado de Santa Catarina - UDESC, \\ CEP 89219-710, Joinville, SC, Brasil \\ ${ }^{b}$ Universidade Federal do Paraná - UFPR, CEP 81531-990, Curitiba, PR, Brasil
}

Received: June 25, 2014; Revised: October 19, 2014

\begin{abstract}
In this work, nanocomposites with simultaneous dispersion of carbon nanotubes and clays in a high density polyethylene (HDPE) matrix were prepared. Two different processes of preparation were employed: solution or melt intercalation. Two different montmorillonite clays were used separately: a natural (MMT-Na) or an organoclay (MMT-30B) and it was used multiwalled carbon nanotubes (MWCNT). Thermal properties were evaluated by DSC and TGA, mechanical properties were evaluated by nanoindentetion and morphology was investigated by transmission electronic microscopy (TEM). Alterations of $20 \%$ in crystallinity were detected, increases in Young's modulus up to $12 \%$ were observed and up to $20 \%$ of increase was observed in Oliver-Pharr hardness. It is possible to explain part of those results based on the state of dispersion observed in our TEM results.
\end{abstract}

Keywords: nanocomposites, polyethylene, carbon nanotube, Clay, mixing methods

\section{Introduction}

The high density polyethylene (HDPE) is one of the most used polymeric materials in the world, due to their properties as chemical resistance, easy processing and its atoxicity. However, the HDPE has a poor mechanical performance, especially in structural applications, limiting their use ${ }^{1}$. Mechanical properties of HDPE can be improved by reinforcing the matrix with rigid nanoparticles as organoclays ${ }^{2}$. When carbon nanotubes are incorporated, electrically and thermally conductive polymer composites can be produced, and at the same time reinforcement can be obtained ${ }^{3,4}$.

Recently, it is possible to find in the literature a route of nanocomposites production which combine clays, carbon nanotubes and polymeric matrices ${ }^{5-12}$. Two different route was observed: 1) carbon nanotubes are synthesized (usually by chemical vapor deposition) on clay surfaces which are subsequently incorporated into polymer matrixes ${ }^{7,8,11}, 2$ ) clays and carbon nanotubes are incorporated separately into polymer matrixes ${ }^{5,6,9,10,12}$. Ma et al. ${ }^{10}$ found experimentally that there is a strong synergistic effect when carbon nanotubes and nanoclay are mixed simultaneously in an ABS matrix. They observed an increase in flame retarding of the nanocomposite. In addition, using concepts of linear viscoelastic properties it was concluded that the coexistence of carbon nanotubes and clay (MMT-Na) promotes a greater obstacle for movements of polymeric chains. Zhang et al. ${ }^{7}$ achieved increases of $400 \%$ in Young's modulus clay/ CNT/polyamide 6 in relation to neat polyamide 6 , and increases up to $70 \%$ in the Vickers hardness compared to

*e-mail: daniela.becker@udesc.br the neat polymer. Wang et al. ${ }^{8}$ achieved increases of $100 \%$ in impact strength and $70 \%$ in the Vickers hardness of composites with epoxy / clay / CNT. Zhang and Wang ${ }^{6}$ reported increases of $50 \%$ in the Young's modulus of the nanocomposites. These authors could observe, by means of $\mathrm{x}$-rays diffraction, possible clay exfoliation states when using the carbon nanotube in the nanocomposites. Liu and Grunlan ${ }^{9}$ reported increases in electrical conductivity in the order of $10^{4}\left({\mathrm{~S} . \mathrm{cm}^{-1}}^{-1}\right)$ and in storage modulus up to $30 \%$ on an epoxy matrix using single wall carbon nanotubes/clays. Levchenko et al. ${ }^{12}$ investigated the influence of simultaneous addition of organo-clay and multi-walled carbon nanotube on electrical and mechanical properties of polypropylene. They observed that percolation threshold was reduced and the organo-clay do not influence significantly on the thermal and mechanical properties.

The nanocomposites can be prepared by a combination of melt or/and solution compounding or/and by in situ polymerization. The melt compounding is most economically attractive and environmentally viable since does not require solvent and can be performed using scalable melt extrusion. However, the dispersion is particularly difficult because the high viscosity of the polymer and the low bulk density of the nanoparticles which makes feeding into extruders very difficult. The solution blending has the advantage of low viscosity of the solution that allows the particle dispersion ${ }^{13}$. Filippi et al..$^{14}$ suggested that from a scientific point of view, a comparison of the structure and morphology of nanocomposites obtained by different routes of preparation is useful to clarify the relative importance of 
the parameters that influence the dispersion processes, such as the stress involved in melt-compounding, the temperature, the compatibility for instance.

In the present work, morphological, thermal and mechanical properties of HDPE nanocomposites prepared by different compounding methods with two different clays and carbon nanotubes have been investigated. From the best of our knowledge it is the first investigation using HDPE, nanoclays and carbon nanotubes for preparing nanocomposites.

\section{Experimental}

The resin used in this work was high density polyethylene (HDPE) HC760LS-L, supplied by Braskem $\left(M_{n}=23,000 \mathrm{~g} / \mathrm{mol} \mathrm{e}_{\mathrm{w}}=68,500 \mathrm{~g} / \mathrm{mol}\right)$. The montmorillonite clays were provided by Southern Clay Co.: Cloisite ${ }^{\circledR} \mathrm{Na}^{+}$ and Cloisite ${ }^{\circledR}$ 30B, named as MMT-Na+ and MMT-30B, respectively. The MMT-30B is an organoclay, with MT2EtOH (methyl, tallow, bis-2-hydroxyethyl, quaternary ammonium) providing its organophilic nature and $\mathrm{d}_{001}$ of

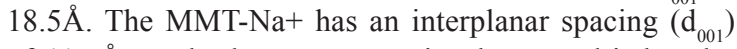
of $11.7 \AA$. Both clays were previously oven-dried under vacuum, for 48 hours at $60^{\circ} \mathrm{C}$. MWCNTs were supplied by Shengdu Organic Chemicals, commercially denominated as TNIM4, with purity higher than $85 \%$, electrical conductivity of $100 \mathrm{~S} / \mathrm{cm}$, diameters ranging from $10-30 \mathrm{~nm}$ and lengths of about $10-30 \mu \mathrm{m}$. All experiments were performed using $3 \mathrm{wt} \%$ of clay relative to the mass of HDPE, except the neat system. In some samples, a constant mass fraction of $1 \mathrm{wt} \%$ of MWCNT was used. The nanocomposite samples prepared in this work were obtained by solution and melt compounding. The adopted nomenclature for this work is shown in Table 1.

\subsection{Solution intercalation}

The $10 \mathrm{~g}$ of polyethylene was dissolved in $1000 \mathrm{~mL}$ of 1,2 diclorobenzene. The solution was maintained at $130^{\circ} \mathrm{C}$ and stirred until complete polymer dissolution. The appropriate volume of nanoparticles were added in another flask with $80 \mathrm{~mL}$ of 1,2 diclorobenzene. This mixture was previously manually stirred, followed by sonication for 30 minutes at $150 \mathrm{~W}, 20 \mathrm{KHz}$ and $20 \%$ of amplitude, using a Sonics VCX 750 sonicator device with a tip at $130^{\circ} \mathrm{C}$. Before the sonication, the solution with nanoparticles were added into the polymer solution and magnetic stirring was used to mix the components for ten minutes. Methanol was used as a non-solvent to separate the nanocomposite. The precipitation was done at $6^{\circ} \mathrm{C}$ and kept at this temperature for $8 \mathrm{~h}$. The nanocomposite was filtered and dried under vacuum at $60^{\circ} \mathrm{C}$ for $48 \mathrm{~h}$.

\subsection{Melt intercalation}

The melt intercalation was performed in a Haake torque rheometer with a $50 \mathrm{~cm}^{3}$ mixing chamber and standard rotors, operated at $180^{\circ} \mathrm{C}$ and $50 \mathrm{rpm}$ for $10 \mathrm{~min}$. The nanoparticles were added after 2 minutes of mixture.

\subsection{Compression molding}

The nanocomposites were compressed and molded into disks of $2 \mathrm{~mm}$ thickness and $50 \mathrm{~mm}$ diameter using a hydraulic press at $180^{\circ} \mathrm{C}$ for $5 \mathrm{~min}$ by applying a force of $5 \mathrm{~T}$ and cooled with water to room temperature.

\subsection{Characterization techniques}

The melting and cristallization temperature and crystallinity degree were obtained by differential scanning calorimetry (DSC), in a NETZSCH DSC 200 F3 equipment, with a heating rate of $10^{\circ} \mathrm{C} / \mathrm{min}$, from 30 to $300^{\circ} \mathrm{C}$ (under nitrogen atmosphere). The percent of crystallinity (Xc) was determined from the enthalpy of crystallization of HDPE, Equation 1, using a value of $\Delta \mathrm{H}_{\mathrm{f}}{ }_{\mathrm{f}}=293 \mathrm{~J} / \mathrm{g}$ for HDPE $100 \%{ }^{15}$ crystalline and the enthalpy values were corrected for HDPE weight present in the nanocomposite.

$X_{c}=\left(\frac{\Delta H_{\text {amostra }}^{o}}{\Delta H_{f}^{0}}\right) \times 100$

The weight loss was obtained by thermogravimetric analysis (TGA), in a Shimadzu TGA-50 equipment with a heating rate of $20^{\circ} \mathrm{C} / \mathrm{min}$ from $30^{\circ} \mathrm{C}$ to $500^{\circ} \mathrm{C}$ (under nitrogen atmosphere). The nanoidentation was performed on Nanoindenter XP equipment using a Berkovich indenter. By applying the method of Oliver and Pharr ${ }^{16}$, it was performed measurements of elastic modulus and nanohardness through sixteen indentations arranged in a

Table 1. Nomenclature and composition of the samples.

\begin{tabular}{|c|c|c|c|}
\hline Samples & Mixing Method & $\%$ MWCNT & Quantity and type of Clay(\%) \\
\hline PEm & Melt & 0 & 0 \\
\hline PENam & & 0 & $3 \%$ Cloisite ${ }^{\circledR} \mathrm{Na}+$ \\
\hline PE30Bm & & 0 & 3\% Cloisite ${ }^{\circledR}$ 30B \\
\hline PENCm & & 1 & 0 \\
\hline PENC Nam & & 1 & $3 \%$ Cloisite $^{\circledR} \mathrm{Na}+$ \\
\hline PENC30Bm & & 1 & 3\% Cloisite ${ }^{\circledR} 30 \mathrm{~B}$ \\
\hline PEs & Solution & 0 & 0 \\
\hline PENas & & 0 & $3 \%$ Cloisite ${ }^{\circledR} \mathrm{Na}+$ \\
\hline PE30Bs & & 0 & 3\% Cloisite ${ }^{\circledR}$ 30B \\
\hline PENCs & & 1 & 0 \\
\hline PENCNas & & 1 & $3 \%$ Cloisite ${ }^{\circledR} \mathrm{Na}+$ \\
\hline PENC30Bs & & 1 & 3\% Cloisite ${ }^{\circledR} 30 \mathrm{~B}$ \\
\hline
\end{tabular}


matrix of indentations of $4 \times 4$. Each indentation was spaced $200 \mathrm{~mm}$ from the previous. It was used a maximum load of $50 \mathrm{mN}$, with 8 cycles of loading and unloading in each indentation. X-rays diffraction measurements were made with a Shimadzu XRD 6000 diffractometer, using CuK $\alpha$ radiation at scan rate of $2 \% \mathrm{~min}$.

Ultra thin sections of $30 \mathrm{~nm}$ were cut from the compression molded disks with a diamond knife at $-85^{\circ} \mathrm{C}$, using a RCM Power Tome X Ultramicrotome. Sections were collected on the surface of a water-dimethylsulfoxide $(60 / 40 \mathrm{v} / \mathrm{v})$ bath cooled at $-60^{\circ} \mathrm{C}$. A JEOL JEM-2100 transmission electron microscope at $200 \mathrm{kV}$ was used for obtaining the images.

\section{Results and Discussion}

Figure 1 shows TEM images of the samples containing clay and CNTs separately for both intercalation methods. It can be observed that samples with MMT-Na+ (Figures 1a, b) the intercalation methods do not significantly alter the clay intercalation. In both conditions it is possible to observe aggregates of clay platelets. However, samples with MMT-30B clay present an intercalation/exfoliation state for solution intercalation method (Figure 1d) and present aggregates of clay platelets for melt intercalation (Figure 1c). Some authors observed significant levels of intercalation or exfoliation in linear low density polyethylene prepared by solution ${ }^{17}$ and microcomposites are known to be produced by melt intercalation ${ }^{18}$. Other authors obtained microcomposites by solution intercalation and better intercalation state by melt blending ${ }^{14,19}$. Sinha Ray and Okamoto ${ }^{20}$ cited that the intercalation only occurs for certain polymer/solvent pairs and is suitable for polymer with low polarity into layer structures. Besides, the interaction of clay and solvent used is very important. The organophilic character of MMT30B clay allowed its swelling when in the presence of the organic solvent 1,2 diclorobenzene, facilitating intercalation in polyethylene matrix. Samples with MWCNTs present a different behavior, when prepared by melt intercalation (Figure 1e) presented better dispersion of carbon nanotubes than samples obtained by solution intercalation (Figure 1f), unlike what was observed in the literature ${ }^{21}$. This behavior can be related with the fact that in the solution intercalation the mixture was maintained for 10 minutes of mechanical stirring after sonication of the nanoparticles in the solvent, this could be enough to allow reagglomeration of carbon nanotubes before solvent extraction. It could be better to use high energy sonication instead mechanical stirring when particles and matrix were mixture.

The TEM images of the samples containing clay with CNTs are present in Figure 2. It should be pointed out that simultaneous dispersion of CNT and clay does not

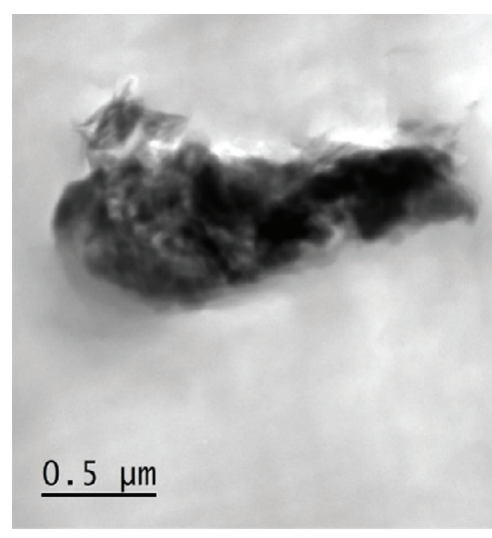

(a)

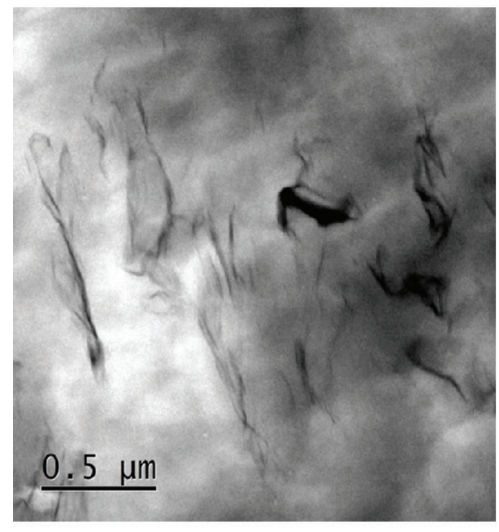

(d)

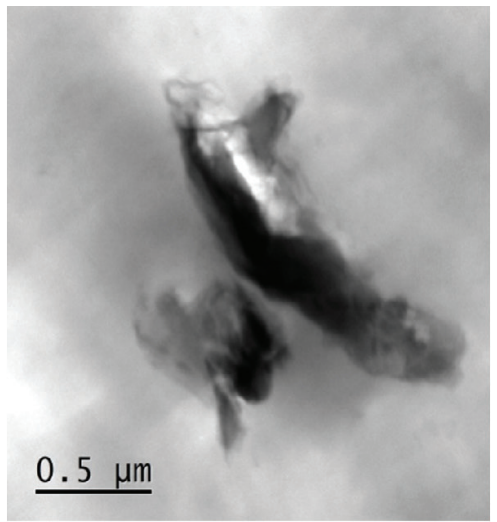

(b)

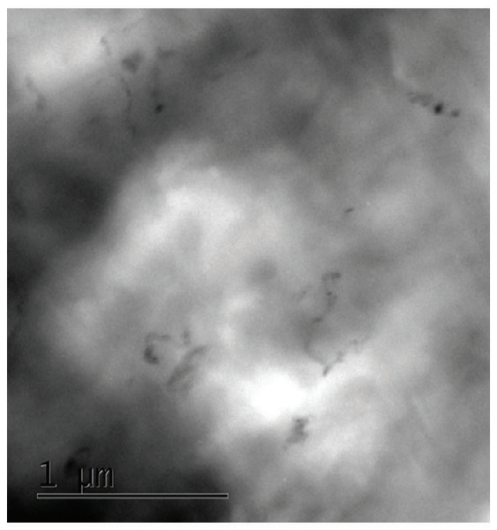

(e)

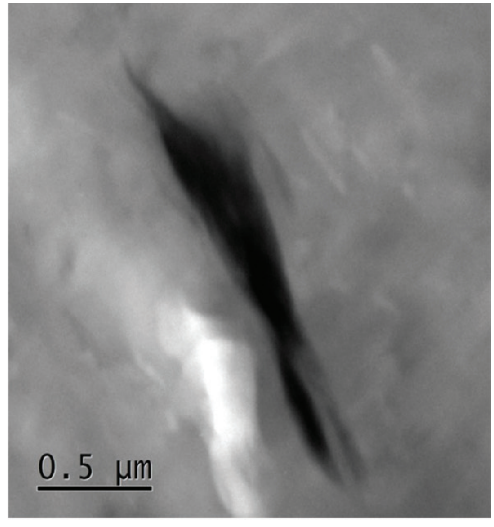

(c)

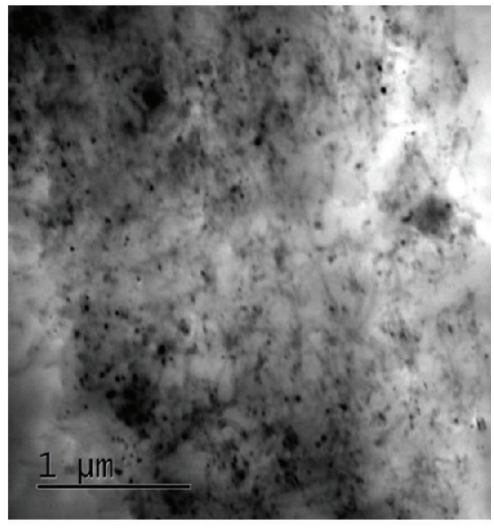

(f)

Figure 1. TEM micrographs of (a) PENam; (b) PENas; (c) PE30Bm; (d) PE30Bs; (e) PENCm; (f) PENCs. 
significantly alter the nanoclays dispersion. For both clays, in solution intercalation the NTCs agglomerates showed a preferential trend of being around the clay clusters (Figures 2a, b, e, f). In melt intercalation, the behavior for both clays was slightly different. For MMT-30B (Figures 2c, e) the CNT was better dispersed and was possible to observed some of them around the clay clusters.
The images of the samples with MMT-Na ${ }^{+}$showed a lower attraction of CNT to the clay particles and some CNT agglomerates (Figures 2f, g).

The X-rays diffraction patterns of neat HDPE and nancomposites for different mixing process are presented in Figure 3. All samples show two distinct (110) and (200) reflection peaks related to the orthorhombic crystal structure

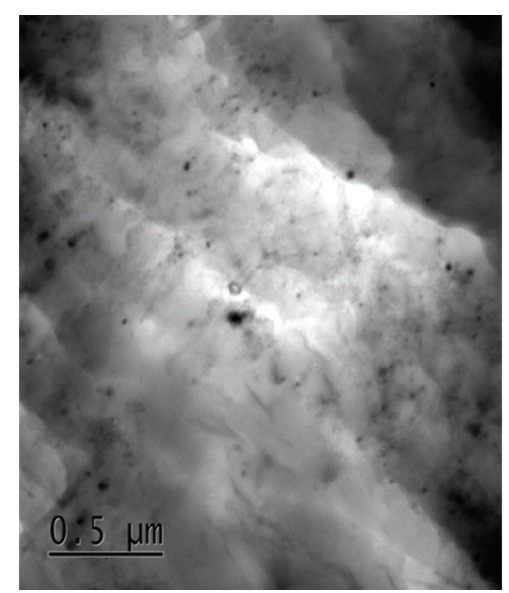

(a)

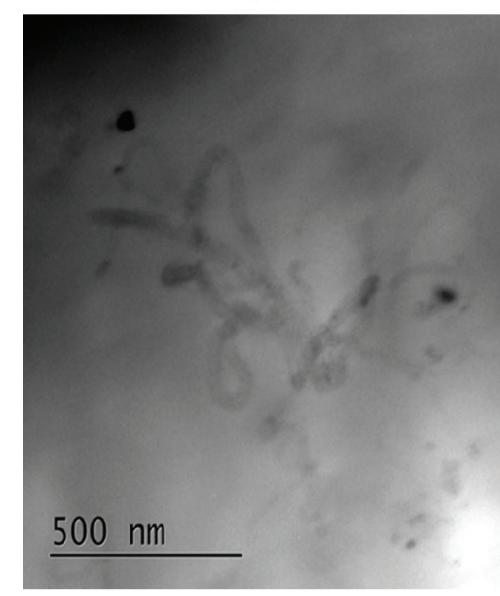

(d)

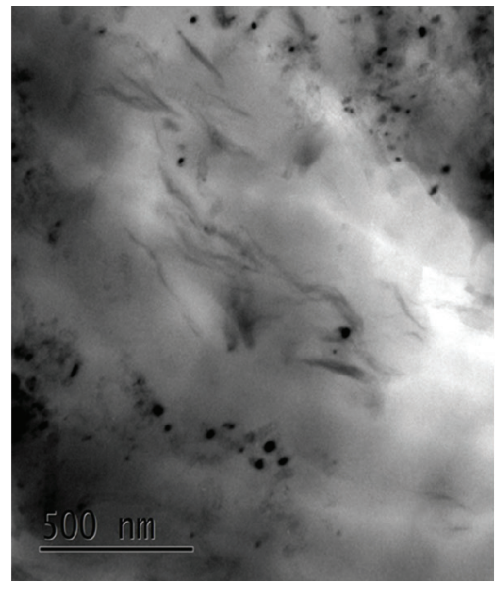

(b)

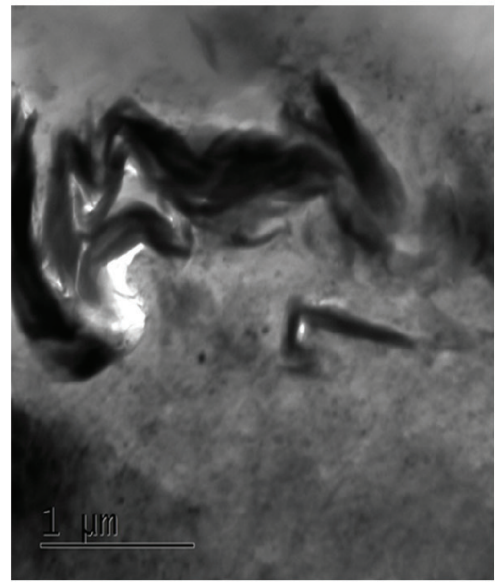

(e)

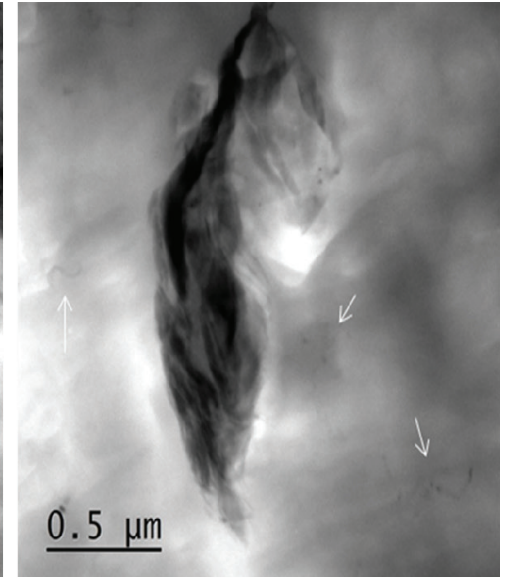

(c)

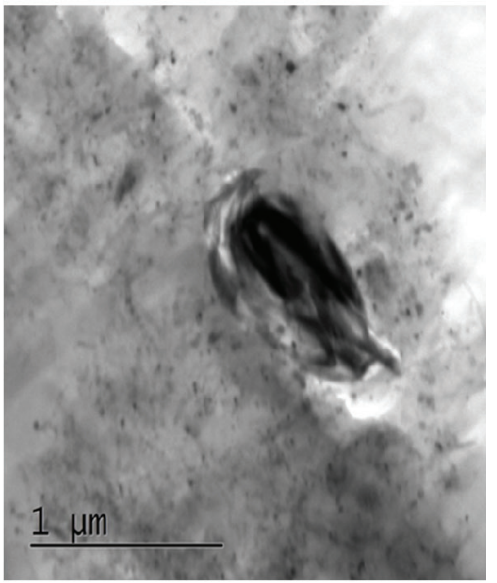

(f)

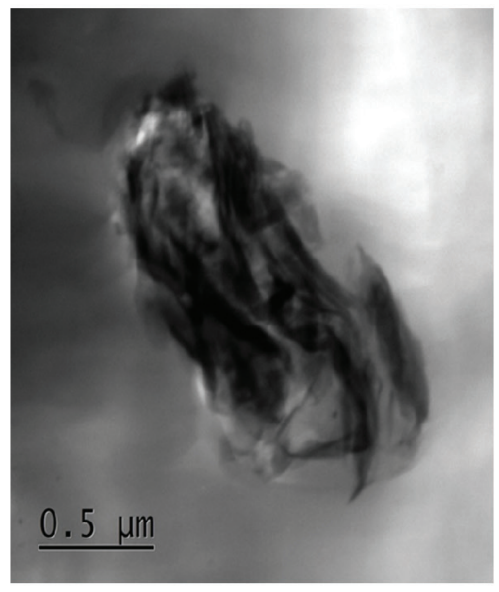

(g)

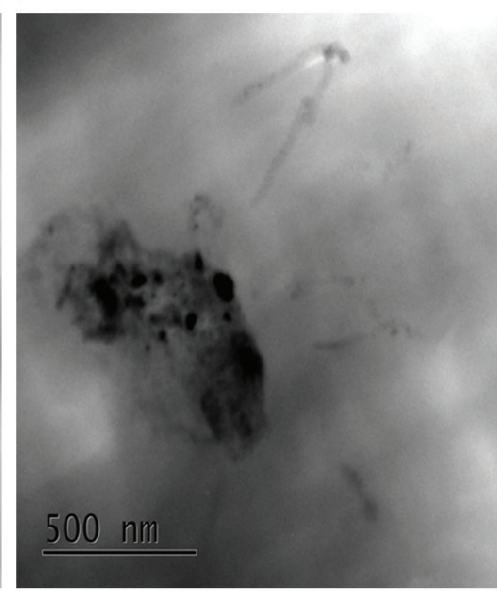

(h)

Figure 2. TEM micrographs of (a) and (b) PE30BNCs; (c) and (d) PE30bNCm; (e) and (f) PENaNCs; (g) and (h) PENaNCm. 
of polyethylene ${ }^{22}$. The amorphous halo for nanocomposites obtained by melt intercalation present smaller regions than for those obtained by solution intercalation. The lower viscosity of the medium in the solution intercalation method very probably allowed nanoparticles to get diffused more rapidly than in melt intercalation, in this way a more homogeneous dispersion of nanoparticles can be obtained and more CNTs or clays can act as sites for crystallization as already very well pointed out in the literature ${ }^{22-26}$. In addition, it can be observed a diffraction peak locates at $2 \theta=20^{\circ}$ for the nanocomposites with CNT prepared by solution (PENCs). This peak can be indexed as the plane (010) plane of the monoclinic form of $\mathrm{PE}^{22}$. In general, the monoclinic form of $\mathrm{PE}$ is metastable in pure polymers and is only obtained under either high pressure ${ }^{23}$ or large deformations, for example, during mechanical stretching ${ }^{24}$, some authors also observed the formation of monoclinic PE crystals in nanocomposites with carbon nanotubes ${ }^{25,26}$. Zhang et al. ${ }^{26}$ affirmed that the formation of monoclinic PE crystals in nanocomposites with carbon nanotube demonstrates that the CNTs act as a nucleating agent for the monoclinic PE crystallization.

In Table 2 and Figure 4 is presented the DSC results for nanocomposites, all the results are from duplicated runs, except PE30Bs that was tested three times. It is possible to see that the main melting temperature was kept almost constant. The addition of the organoclay (30B) presents the higher reduction of crystallinity degree in solution blending. This behavior can be related to the intercalated/ exfoliated state observed in TEM image (Figure 1d). Some authors ${ }^{27,28}$ also observed that the addition of nanoparticles, clays in general, decreased the crystallinity of polyethylene. Tracz et al. ${ }^{28}$ related nucleating and ordering effects to a large extent on the nanostructure of its surface, small nanoparticles do not have any nucleating effect, moreover they act as obstacles for crystallization on polyethylene. The authors also cited that even though the nanoparticles agglomerates may nucleate, the overall influence of the nanoparticles can be considered to be retardant effect and decrease the crystallinity of the matrix.

The addition of MWCNT's alone increased the crystallinity degree in the samples prepared by both

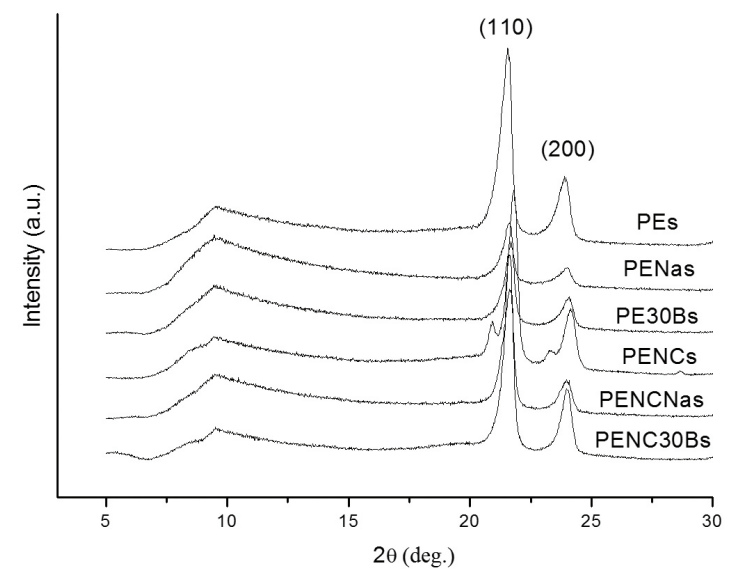

(a) intercalation methods. It is also observed that the addition of carbon nanotubes simultaneous with clay increased the crystallinity degree for both clays prepared by solution blending. The higher increased was in the PENC30Bs. Some authors ${ }^{29-31}$ observed that crystallinity of HDPE increases with an addition of carbon nanotubes, and Kanagaraj et al. ${ }^{29}$ suggested that nanotubes not only nucleate polymer crystallization, but can also be used to propagate the crystallization for a large distance from their surface. By melt intercalation, the MWCNT addition leads to a decreased in the crystallinity for both clays. This behavior can be related with the dispersion state of MWNCT as seen in TEM images (Figures 1 and 2), in the nanocomposites obtained by melt intercalation the MWNCT had a more homogeneous dispersion and very probably can act as obstacles for crystallization on polyethylene as commented by Tracz et al. ${ }^{28}$.

Thermogravimetric analysis (TGA) of nanocomposites for different mixing process is shown in Figure 5 and some important data are summarized and presented in Table 3. In general, the nanocomposites obtained by melting process showed no change in thermal behavior regardless of nanoparticles added. The nanocomposites prepared

Table 2. DSC result of PE and nancomposites for different mixing process.

\begin{tabular}{lccc}
\hline \multicolumn{1}{c}{ Samples } & $\mathbf{T}_{\mathbf{C}}\left({ }^{\circ} \mathbf{C}\right)$ & $\mathbf{T}_{\mathbf{m}}\left({ }^{\circ} \mathbf{C}\right)$ & $\mathbf{X c} \mathbf{( \% )}$ \\
\hline PEm & 115 & 135 & $67 \pm 1.4$ \\
PENam & 115 & 135 & $64 \pm 6.4$ \\
PE30Bm & 115 & 133 & $68 \pm 3.5$ \\
PENCm & 117 & 132 & $72 \pm 0.7$ \\
PENC Nam & 114 & 133 & $64 \pm 0.7$ \\
PENC30Bm & 114 & 132 & $58 \pm 1.4$ \\
PEs & 115 & 135 & $63 \pm 7.1$ \\
PENas & 115 & 132 & $60 \pm 1.4$ \\
PE30Bs & 115 & 134 & $44 \pm 1.4$ \\
PENCs & 112 & 133 & $65 \pm 1.4$ \\
PENCNas & 110 & 133 & $58 \pm 1.4$ \\
PENC30Bs & 112 & 133 & $61 \pm 1.4$ \\
\hline
\end{tabular}

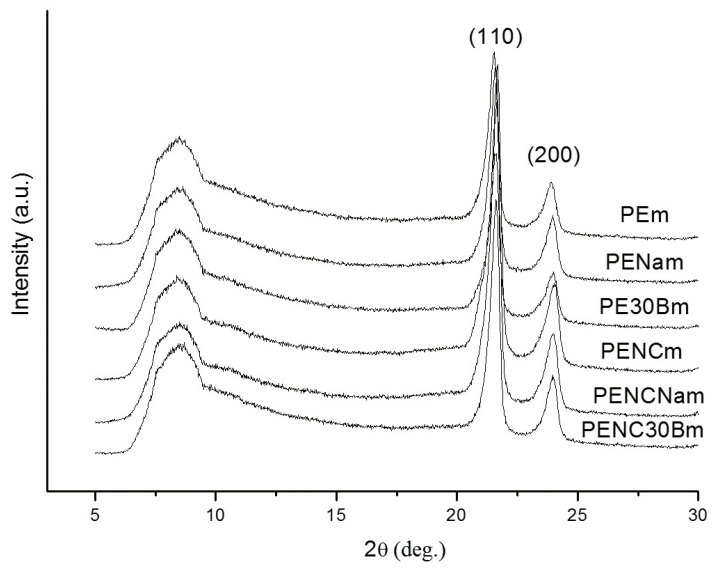

(b)

Figure 3. X-ray diffraction patterns of PE and nancomposites for (a) solution (b) melt intercalation. 


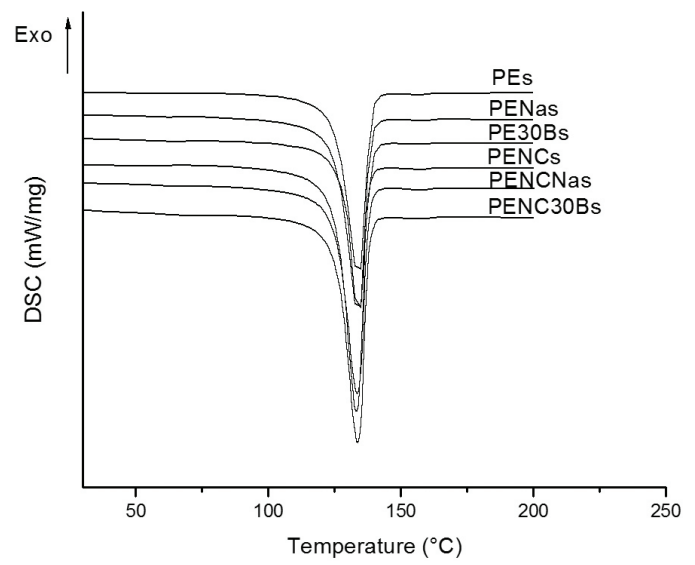

(a)

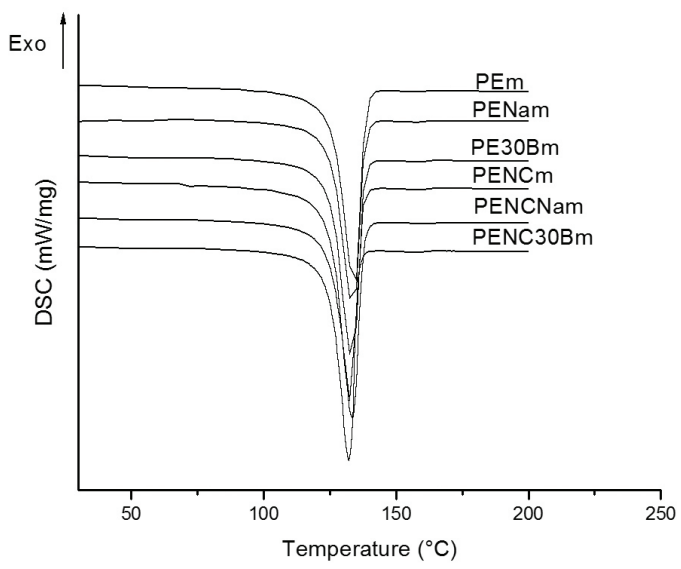

(b)

Figure 4. DSC curves for nanocomposites mixing by (a) solution; (b) melting.

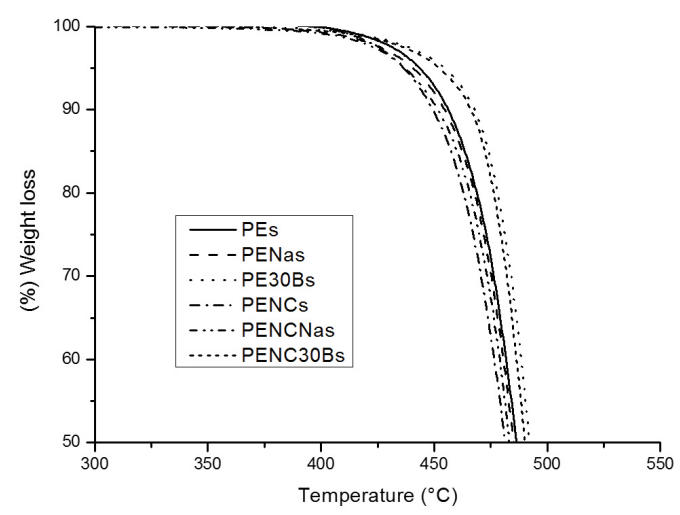

(a)

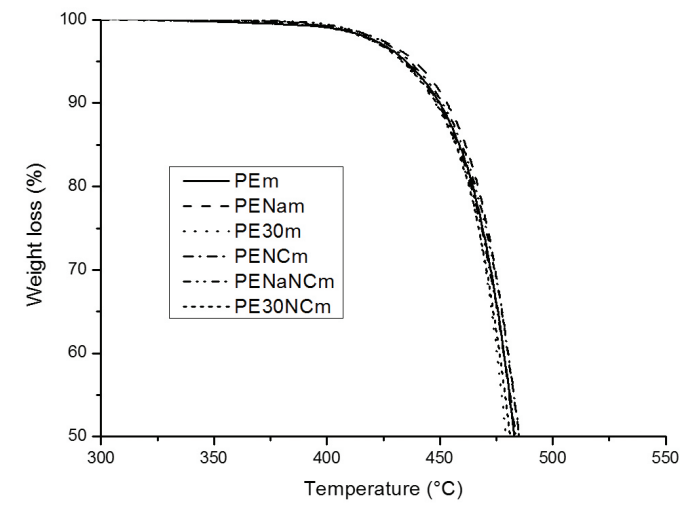

(b)

Figure 5. TGA thermograms for nanocomposites mixing by (a) solution; (b) melting.

Table 3. Data obtained from TGA analysis of nanocomposites for different mixing process.

\begin{tabular}{lcc}
\hline \multicolumn{1}{c}{ Samples } & $\mathbf{T}_{\text {onset }}\left({ }^{\circ} \mathbf{C}\right)$ & $\mathbf{T}_{\mathbf{5 \%}}\left({ }^{\circ} \mathbf{C}\right)$ \\
\hline Pem & 402 & 435 \\
PENam & 406 & 438 \\
PE30Bm & 401 & 433 \\
PENCm & 404 & 434 \\
PENC Nam & 408 & 436 \\
PENC30Bm & 404 & 433 \\
Pes & 417 & 443 \\
PENas & 407 & 440 \\
PE30Bs & 418 & 454 \\
PENCs & 413 & 436 \\
PENCNas & 404 & 436 \\
PENC30Bs & 415 & 452 \\
\hline
\end{tabular}

Tonset - temperature of onset decomposition; T5\% - temperature of 5\% of weight loss.

by solution intercalation with organoclay (PE30Bs and PENC30Bs) present higher thermal stability than neat PEAD, despite the reduction in crystallinity degree. This behavior can be explained by the intercalated/exfoliated state observed in TEM image (Figure 1d). Zhao et al. ${ }^{32}$ suggested that adding low fraction of organoclay to the polymer matrix, the clay layers should be well dispersed, the barrier effect should improve the thermal stability. El Achaby et al. ${ }^{33}$ also suggested that clay silicates exhibit a better barrier action and their incorporation into the polymer matrix increase the thermal stability. This improvement in the thermal stability can be explained since clay can make difficult the diffusion of the emission of the gaseous degradation products because can act as a mass transport barrier of this volatile product ${ }^{34,35}$.

All nanocomposites, in general, present an increase in the Young's Modulus, as can be seen in Figure 6a. In the samples prepared by melt intercalation, the addition of MWCNT's increased 4\% the Young's modulus, the simultaneous addition of clays and MWCNT's increased the Young's modulus by $10 \%$ for both clays. In the samples prepared by solution intercalation, the addition of clays separately, increased the Young's modulus by $8 \%$ (PENas) and $12 \%$ (PE30s). It should be pointed out that despite the lower cristalinity degree of sample PE30s, it was observed an increased in Young's modulus, this behavior can be explained by the a mechanism where stress is transfer from the matrix to the disperse rigid phase which is related with the intercalated/exfoliated state observed in TEM image (Figure 1d) and a large aspect ratio of the nanoclays ${ }^{19,33}$. 


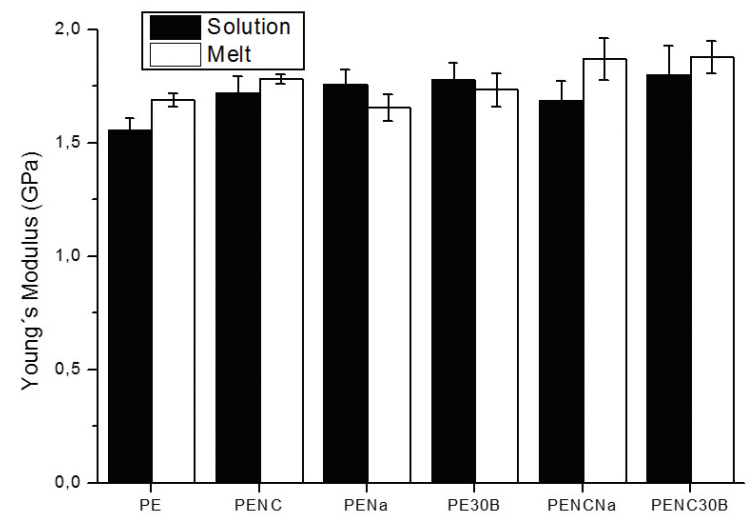

(a)

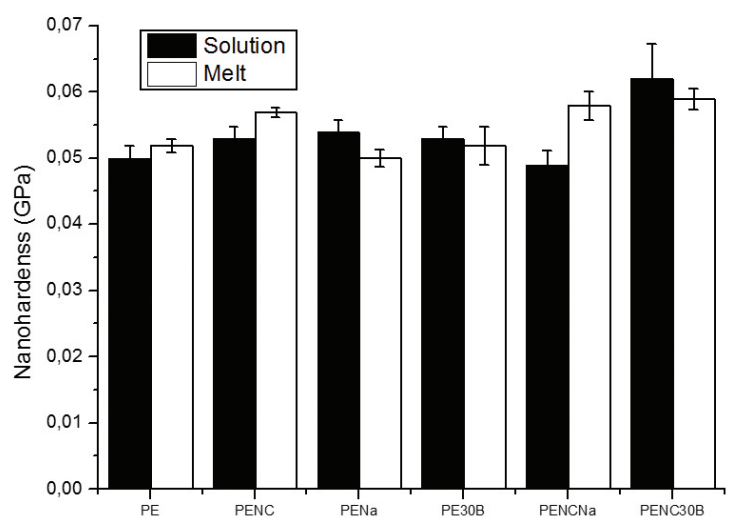

(b)

Figure 6. (a) Young's modulus of nanocomposites and (b) Nanohardness of nanocomposites prepared by solution and melt intercalation.

The addition of MWCNT's to the samples prepared by melt intercalation increased by $8 \%$ the Young's modulus. The highest degree of reinforcement was obtained by the addition of MMT-30B and MWCNT's in the sample prepared by solution intercalation where $28 \%$ of increase was reached.

It was possible to realize that MWCNT's can reinforce the matrix alone and to help the reinforcement of the matrix when dispersed simultaneously with clays. Related to clays, it was possible to see that organoclays caused more reinforcement when solution intercalation is employed. When the dispersions of MWCNT's and clays (MMT30B) are simultaneous the highest degree of reinforcement was obtained. It should be noted that in the case of melt intercalation results for MMT-Na+ and MWCNT's dispersed simultaneously gave similar results as in the case of MMT-30B and MWCNT's.

In the Figure $6 \mathrm{~b}$ is possible to see that the addition of nanoparticles increased the nanohardness related to neat PEAD. The melt compounding method in three different conditions, PENC, PENCNa and PENC30B, presented a higher nanohardness than the neat polymer whereas the solution intercalation in only one which was PENC30B. It is well know that hardness it is not a material property and it is dependent of the method employed for measurement and also the scale used, i.e. nano or microscale. The presence of nanoparticles constraint the mobility of the polymer chains and higher forces are required to cause plastic deformation. The highest degree of hardness was obtained by the addition of MMT-30B and MWCNT's in the sample prepared by solution intercalation where $24 \%$ of increase was reached. This behavior can be explained by the intercalated/exfoliated state observed in TEM image (Figure 2a), more interface area means more interphase which is going to generate more possibility for interaction and to increase the resistance to plastic deformation. The modulus of elasticity of this sample

\section{References}

1. Vega JF, Muñoz-Escalona A, Santamaría A, Muñoz ME and Lafuente P. Comparison of the rheological properties of metallocene-catalyzed and conventional high-density is also the highest one indicating that the stress transfer from matrix to nanoparticle is more effective here.

\section{Conclusions}

The results of this study showed that it is possible to prepare nanocomposites of HDPE with simultaneous dispersion of MWCNT/MMT by means of solution or melting intercalation. The preparation process and type of nanoclay influenced differently the nanocomposites morphology. According to the TEM images, MWCNT presented better dispersion in the nancomposites prepared by melting mixing and nanoclay present smaller agglomerates in the samples prepared by solution mixing. It is also observed that whit simultaneous dispersion MMT-30B is more compatible with CNTs than MMT- $\mathrm{Na}^{+}$.

Concerning the thermal properties, the preparation methods influenced more than the type of particles. The degree of crystallinity is smaller in general in nanocomposites prepared by solution intercalation method. The thermal stability of nanocomposites prepared by solution intercalations is higher than those prepared by melting intercalation. This is also an indication that nanoparticles are more homogeneously disperse in the nanocomposites prepared by solution intercalation than melting intercalation method and they are able for acting more as a barrier for energy transport.

Concerning to the mechanical properties, both methods of preparation caused increases in modulus and hardness. The addition of both nanoparticles in both methods of preparation increased mechanical properties.

\section{Acknowledgements}

The authors acknowledge the financial support by FAPESC and CNPq.

polyethylenes. Macromolecules. 1996; 29(3):960-965. http:// dx.doi.org/10.1021/ma9504633.

2. Paul DR and Robeson LM. Polymer nanotechnology: Nanocomposites. Polymer. 2008; 49(15):3187-3204. http:// dx.doi.org/10.1016/j.polymer.2008.04.017. 
3. Kim H, Kobayashi S, AbdurRahim MA, Zhang MJ, Khusainova A, Hillmyer MA, et al. Graphene/polyethylene nanocomposites: effect of polyethylene functionalization and blending methods. Polymer. 2011; 52(8):1837-1846. http:// dx.doi.org/10.1016/j.polymer.2011.02.017.

4. Kim H, Abdala AA and Macosko CW. Graphene/polymer nanocomposites. Macromolecules. 2010; 43(16):6515-6530. http://dx.doi.org/10.1021/ma100572e.

5. Georgakilas V, Bourlinos A, Gournis D, Tsoufis T, Trapalis C, Mateo-Alonso A, et al. Multipurpose organically modified carbon nanotubes: from functionalization to nanotube composites. Journal of the American Chemical Society. 2008; 130(27):8733-8740. http://dx.doi.org/10.1021/ja8002952. PMid: 18597430

6. Zhang JP and Wang AQ. Synergistic effects of Na+montmorillonite and multi-walled carbon nanotubes on mechanical properties of chitosan film. Express Polymer Letters. 2009; 3(5):302-308. http://dx.doi.org/10.3144/ expresspolymlett.2009.38.

7. Zhang W, Phang IY and Liu T. Growth of Carbon Nanotubes on Clay: Unique Nanostructured Filler for High-Performance Polymer Nanocomposites. Advanced Materials. 2006; 18(1):73-77. http://dx.doi.org/10.1002/adma.200501217.

8. Wang Z, Xu C, Zhao Y, Zhao D, Wang Z, Li H, et al. Fabrication and mechanical properties of exfoliated clay-CNTs/epoxy nanocomposites. Materials Science and Engineering A. 2008; 490(1-2):481-487. http://dx.doi.org/10.1016/j. msea.2008.01.040.

9. Liu L and Grunlan JC. Clay Assisted Dispersion of Carbon Nanotubes in Conductive Epoxy Nanocomposites. Advanced Functional Materials. 2007; 17(14):2343-2348. http://dx.doi. org/10.1002/adfm.200600785.

10. Ma H, Tong L, Xu Z and Fang Z. Synergistic effect of carbon nanotube and clay for improving the flame retardancy of ABS resin. Nanotechnology. 2007; 18(37):375-393. http://dx.doi. org/10.1088/0957-4484/18/37/375602.

11. Chiu C-W, Huang T-K, Wang Y-C, Alamani BG and Lin J-J. Intercalation strategies in clay/polymer hybrids. Progress in Polymer Science. 2014; 39(3):443-485. http://dx.doi. org/10.1016/j.progpolymsci.2013.07.002.

12. Levchenko V, Mamunya Y, Boiteux G, Lebovka M, Alcouffe $\mathrm{P}$, Seytre G, et al. Influence of organo-clay on electrical and mechanical properties of PP/MWCNT/OC nanocomposites. European Polymer Journal. 2011; 47(7):1351-1360. http:// dx.doi.org/10.1016/j.eurpolymj.2011.03.012.

13. Ajayan PM, Schadler LS and Braun PV, editors. Nanocomposite Science and Technology. Weinheim: WILEY-VCH Verlag GmbH Co; 2003.. http://dx.doi.org/10.1002/3527602127.

14. Filippi S, Marazzato C, Magagnini P, Famulari A, Arosio $\mathrm{P}$ and Meille SV. Structure and morphology of HDPE-gMA/organoclay nanocomposites: effects of the preparation procedures. European Polymer Journal. 2008; 44(4):987-1002. http://dx.doi.org/10.1016/j.eurpolymj.2008.01.011.

15. Sahebian S, Zebarjad SM, Vahdati Khaki J and Sajjadi SA. The effect of nano-sized calcium carbonate on thermodynamic parameters of HDPE. Journal of Materials Processing Technology. 2009; 209(3):1310-1317. http://dx.doi. org/10.1016/j.jmatprotec.2008.03.066.

16. Yan W, Pun CL and Simon GP. Conditions of applying OliverPharr method to the nanoindentation of particles in composites. Composites Science and Technology. 2012; 72(10):1147-1152. http://dx.doi.org/10.1016/j.compscitech.2012.03.019.

17. Qiu L, Chen W and Qu B. Morphology and thermal stabilization mechanism of LLDPE/MMT and LLDPE/LDH nanocomposites. Polymer. 2006; 47(3):922-930. http://dx.doi. org/10.1016/j.polymer.2005.12.017

18. Hotta S and Paul DR. Nanocomposites formed from linear low density polyethylene and organoclays. Polymer. 2004; 45(22):7639-7654. http://dx.doi.org/10.1016/j. polymer.2004.08.059.

19. Minkova L and Filippi S. Characterization of HDPE-g-MA/clay nanocomposites prepared by different preparation procedures: Effect of the filler dimension on crystallization, microhardness and flammability. Polymer Testing. 2011; 30(1):1-7. http:// dx.doi.org/10.1016/j.polymertesting.2010.10.007.

20. Sinha Ray S and Okamoto M. Polymer/layered silicate nanocomposites: a review from preparation to processing. Progress in Polymer Science. 2003; 28(11):1539-1641. http:// dx.doi.org/10.1016/j.progpolymsci.2003.08.002.

21. Kanagaraj S. Polyethylene Nanotube Nanocomposites. In: Mittal V, editor. Polymer Nanotube Nanocomposites: Synthesis, Properties, and Applications. New York: John Wiley \& Sons; 2010.

22. Uehara H, Nakae M, Kanamoto T, Ohtsu O, Sano A and Matsuura K. Structural characterization of ultrahigh-molecularweight polyethylene reactor powders based on fuming nitric acid etching. Polymer. 1998; 39(24):6127-6135. http://dx.doi. org/10.1016/S0032-3861(98)00102-5.

23. Fontana L, Vinh DQ, Santoro M, Scandolo S, Gorelli FA, Bini $\mathrm{R}$, et al. High-pressure crystalline polyethylene studied by $\mathrm{x}$-ray diffraction and ab initio simulations. Physical Review B. 2007; 75(17):1-11. http://dx.doi.org/10.1103/PhysRevB.75.174112.

24. Butler MF, Donald AM, Bras W, Mant GR, Derbyshire GE and Ryan AJ. A real time simultaneous small and wide angle Xray scattering study of in-situ deformation of isotropic polyethylene. Macromolecules. 1995; 28(19):6383-6393. http://dx.doi.org/10.1021/ma00123a001.

25. Liu Z, Yu M, Wang J, Li F, Cheng L, Guo J, et al. Preparation and characterization of novel polyethylene/carbon nanotubes nanocomposites with core-shell structure. Journal of Industrial and Engineering Chemistry. 2014; 20(4):1804-1811. http:// dx.doi.org/10.1016/j.jiec.2013.08.034.

26. Zhang S, Lin W, Wong C-P, Bucknall DG and Kumar S. Nanocomposites of carbon nanotube fibers prepared by polymer crystallization. ACS Applied Materials \& Interfaces. 2010; 2(6):1642-1647. http://dx.doi.org/10.1021/am1001663. PMid:20507070

27. Huang X, Jiang P, Kim C, Duan J and Wang G. Atomic Force Microscopy Analysis of Morphology of Low Density Polyethylene Influenced by Al Nano- and Microparticles. Journal of Applied Polymer Science. 2008; 107(4):2494-2499. http://dx.doi.org/10.1002/app.27357.

28. Tracz A, Kuncinska I, Wostek-Wojciechowska D and Jeszka JK. The influence of micro- and nanoparticles on model atomically flat surfaces on crystallization of polyethylene. European Polymer Journal. 2005; 41(3):501-509. http://dx.doi. org/10.1016/j.eurpolymj.2004.09.019.

29. Kanagaraj S, Varanda FR, Zhil'tsova TV, Oliveira MSA and Simões JAO. Mechanical properties of high density polyethylene/carbon nanotube composites. Composites Science and Technology. 2007; 67(15-16):3071-3077. http://dx.doi. org/10.1016/j.compscitech.2007.04.024.

30. Coleman JN, Cadek M, Blake R, Nicolosi V, Ryan KP, Belton C, et al. High Performance Nanotube-Reinforced Plastics: Understanding the Mechanism of Strength Increase. Advanced Functional Materials. 2004; 14(8):791-798. http://dx.doi. org/10.1002/adfm.200305200. 
31. Assouline E, Lustiger A, Barber AH, Cooper CA, Klein E, Wachtel E, et al. Nucleation ability of multiwall carbon nanotubes in polypropylene composites. Journal of Polymer Science Part B: Polymer Physics. 2003; 41(5):520-527. http:// dx.doi.org/10.1002/polb.10394.

32. Zhao C, Qin H, Gong F, Feng M, Zhang S and Yang M. Mechanical, thermal and flammability properties of polyethylene/clay nanocomposites. Polymer Degradation \& Stability. 2005; 87(1):183-189. http://dx.doi.org/10.1016/j. polymdegradstab.2004.08.005.

33. El Achaby M, Ennajih H, Arrakhiz FZ, El Kadib A, Bouhfid R, Essassi E, et al. Modification of montmorillonite by novel geminal benzimidazolium surfactant and its use for the preparation of polymer organoclay nanocomposites. Composites. Part B, Engineering. 2013; 51:310-317. http:// dx.doi.org/10.1016/j.compositesb.2013.03.009.

34. Duquesne S, Jama C, Le Bras ML, Delobel R, Recourt P and Gloaguen JM. Elaboration of EVA-nanoclay systemscharacterization, thermal behaviour and fire performance. Composites Science and Technology. 2003; 63(8):1141-1148. http://dx.doi.org/10.1016/S0266-3538(03)00035-6.

35. Gilman JW, Jackson CL, Morgan AB, Harris R, Manias E, Giannelis EP, et al. Flammability Properties of PolymerLayered-Silicate Nanocomposites. Polypropylene and Polystyrene Nanocomposites. Chemistry of Materials. 2000; 12(7):1866-1873. http://dx.doi.org/10.1021/cm0001760. 